\title{
Understanding reverse supply chains
}

\section{Regina Frei*, Angela Bines and lain Lothian}

School of Engineering, University of Portsmouth, UK

Email: work@reginafrei.ch

Email: angela.bines@yahoo.co.uk

Email: iain.lothian@myport.ac.uk,

*Corresponding author

\section{Lisa Jack}

Portsmouth Business School,

University of Portsmouth, UK

Email: lisa.jack@port.ac.uk

\begin{abstract}
Reverse supply chains take a variety of forms, depending on the nature of the product, the business model, the stakeholders and other factors. This article will contribute to a better understanding of how different types of reverse supply chains function, how they can be modelled and their performance assessed. The research is based on a semi-structured approach using case studies, interviews and qualitative analysis. A generic RSC model is suggested in conjunction with an analysis of circumstances and factors of influence, with the intention to trigger further investigation. A better understanding of RSC may lead to more companies engaging in returning products and materials to the process of usefulness suggested by the circular economy concept, hence leading to a more sustainable way of running manufacturing businesses.
\end{abstract}

Keywords: reverse supply chain; RSC; reverse logistics; model; framework; performance; environmental performance; economic performance; operational performance; organisational performance.

Reference to this paper should be made as follows: Frei, R., Bines, A., Lothian, I. and Jack, L. (2016) 'Understanding reverse supply chains', Int. J. Supply Chain and Operations Resilience, Vol. 2, No. 3, pp.246-266.

Biographical notes: Regina Frei is a Senior Lecturer in Manufacturing Engineering and Supply Chain Management at the University of Portsmouth, UK. Her research interests include reverse supply chains, circular economy, remanufacturing, automation and intelligent robotic systems. She has over 35 peer-reviewed publications and has been awarded nine research grants. She holds an MSc in Micro-engineering from the Swiss Federal Institute of Technology Lausanne (EPFL), a PhD in Intelligent Manufacturing Systems from the New University of Lisbon, Portugal, and a Post-Graduate Certificate in Academic Practice from Cranfield University, UK. She is a member of the Institution of Engineering and Technology.

Iain Lothian has practical experience in sectors ranging from finance to IT and supply chain management. This began with his undergraduate dissertation on the new product development processes employed at a major IT hardware

Copyright (C) The Author(s) 2017. Published by Inderscience Publishers Ltd. This is an Open Access Article distributed under the CC BY license. (http://creativecommons.org/licenses/by/4.0/) 
OEM. That work later formed part of the book 'Innovation Management and New Product Development' (3rd ed.) by Professor Paul Trott. In 2014, he completed his MSc in Technology Management before becoming a Research Associate for project leading to this article. Since then, he has been leading business improvement projects at the University of Portsmouth, in line with his interest in processes, their performance measurement and improvement.

\begin{abstract}
Angela Lee Bines received her BEng with First Class Honours in Mechanical and Manufacturing Engineering from the University of Portsmouth in 2016. Prior to this she studied Aerospace Engineering, completing a National Certificate in 2011 and a Higher National Diploma in 2014. She has ten years experience in airworthiness, covering a variety of aspects of aviation safety. She was an Airworthiness Engineer at BAE Systems and is currently an Airworthiness Surveyor (Design and Certification) at the UK Civil Aviation Authority. She is a member of the Institution of Mechanical Engineers and STEM Ambassador.

Lisa Jack is a Professor of Accounting in Portsmouth Business School and has published several academic papers and professional reports. She is the author of Accounting and Social Theory: An Introduction and co-edited The Routledge Companion to Accounting Communication. She has a special interest in accounting in agri-food industries and in particular, fraud in the food and drink industry, including returns fraud.
\end{abstract}

\title{
1 Introduction
}

Globalised trade and increasing pressure on resources from both within and beyond organisations require supply chains to become more sustainable, which includes the need for material flows to become regenerative. In this context, there is a growing interest in evaluating the performance of supply chains in terms of sustainability, which includes economical, ecological and social aspects (Svensson, 2007).

Reverse supply chains (RSC) recover parts and products from end consumers or any other stage of the supply chain and feed them back into the supply network for reuse, remanufacturing, recycling or proper disposal. In this way, RSC contribute to manufacturing becoming more sustainable ecologically, economically and socially.

Most companies that manufacture or retail consumer goods have an RSC of some description, to facilitate the return of goods for a variety of reasons. However they might not recognise this as such and may therefore miss out on opportunities to improve the business and environmental performance of their supply chain operations. This is true in highly developed economies, and even more so in developing ones (El Baz et al., 2016). Nevertheless, a positive impact of RSC on the quality of remanufactured products and customer satisfaction levels has been found (El Barky, 2016).

Research has found there are economic, social and environmental factors that may incentivise companies to take a proactive approach to RSC management. The aim of this work is to contribute to a better understanding of RSC, encouraging companies to engage. This article defines terminology in Section 2 and explores the current situation in industry and refers to relevant literature in Section 3. A framework for modelling RSC (Frei et al., 2015) is presented in Section 4, together with examples and discussion of the possible benefits and challenges of establishing an RSC. Section 5 explores shared 
characteristics of different RSC, whereas Section 6 provides analysis and discussion. Finally, Section 7 concludes this article.

\section{Definitions and terminology}

For the purpose of this article, it is important to draw some distinctions between the definitions and terminology used by industry and academia with respect to sustainability in supply chain management, as these can be subjective. This also clarifies the definition of an RSC adopted here.

- Reverse logistics - this concerns primarily the transportation and storage of products and materials being returned or recovered (Guide and van Wassenhove, 2002).

- Green supply chain - green supply chains are environmentally sustainable, without necessarily and explicitly considering their economical and social dimensions (note that the term 'environmentally sustainable' can have more dimensions than just the carbon footprint and the release of harmful/toxic substances into the environment).

- Sustainable supply chain - sustainable supply chains consider environmental, social and economic factors, as derived from customer and stakeholder requirements (Morana, 2013).

- Closed-loop supply chain - strictly speaking, a supply chain is only closed loop when products are returned to their original manufacturer and for their original purpose, sometimes via third parties; the RSC is an open loop if an independent company takes over. However, the main aspect of interest in the scope of this article is for the flow of products/materials to be regenerative, rather than the distinction between an open or closed loop situation.

- $\quad R S C$ - an RSC is concerned with any process that returns products, components and materials back into the circle of productivity. RSCs often require cross-functional and multi-organisational cooperation and even active participation from customers. Possible scenarios include: product recalls; returns of products that were delivered wrongly or got damaged as well as obsolete stock; used products going to a resale market with or without remanufacturing; and products that reached the end of their useful life and get recycled or disposed of properly, possibly recovering energy in the process.

An ideal RSC will incorporate economically, ecologically and socially sustainable practices. However it is important to note that companies may operate their RSC independently of any or all of these factors. Prahinski and Kocabasoglu (2006) define an RSC as "the effective and efficient management of the series of activities required to retrieve a product from a customer and either dispose of it or recover value". Guide and van Wassenhove (2002) suggest that an RSC includes product acquisition; reverse logistics; inspection and disposition; reconditioning; and distribution and sales. 


\subsection{Methodology}

The approach taken in this research consists of literature research, qualitative analysis, as well as semi-structured (and still ongoing) interviews and case studies. The companies involved in this research include small, medium and large enterprises mainly in Europe across various industries, and the focus was on products that retain a high value after use.

\subsection{Research questions}

The presented research aimed to investigate the following main points:

Q1 What is the current state of the art in understanding different types of RSC and assessing their performance?

Q2 What different types of RSC exist and how do they relate to each other?

Q3 What factors influence companies' decisions to engage in RSC and what factors decide whether or not an RSC will be successful?

\section{Literature review}

\subsection{Performance measurement in green and sustainable supply chains}

Ample literature exists on sustainable and green supply chains and the reasons why companies engage (Lee, 2008; Lee and Rhee, 2007), yet there is relatively little on RSC and even less on how to assess their performance. Research carried out on the environmental performance management of supply chains suggests that little agreement exists as to what should be measured nor indeed how it should be carried out. Furthermore, although significant numbers of metrics have been identified in reviews of the literature such as that of Hervani et al. (2005), performance measurement is focused most strongly on those metrics that can be quantified especially in terms of finance. Callado and Jack (2015) found that whilst balanced scorecards are frequently proposed for the assessment of supply chain performance, the selection of actual metrics varies widely between functions across the supply chains. This is even more the case for the underdeveloped area of RSC. Where environmental performance measures have been identified, such as by Azevedo et al. (2011), Bjorklund et al. (2012) and Bai et al. (2012), these are more often linked to green supply chain management practices generally, rather than RSC operations in particular.

McElroy and Engelen (2012) argue that any absolute metrics should be as descriptive as possible to give them meaning or context. For example, this may mean using a metric such as annual energy use with the context being the number of employees to give a per capita amount or units of production. That said, as the authors point out, the context should be meaningful. For example, it would not be appropriate to use the number of pencil sharpeners available to staff as the context for the amount of green house gases emitted. However inter-annual comparison can be made unreliable given that organisation change sometimes quite radically in terms of size and activity. The authors go to the extent of recommending the avoidance of any absolute metrics that fail to take into account such organisational changes, as they are essentially meaningless for comparison purposes. Relative metrics tend to be focused on efficiency, which is not 
necessarily the same as sustainability. McElroy and Engelen (2012) sometimes refer to them as intensity metrics in that they describe the intensity of use of something, e.g., the use of electricity in department A versus that of department B.

Huisman et al. (2004) point out that in many cases the environmental performance of individual products in end-of-life (EOL) processing cannot be determined as such. The reason is that individual products are not normally treated as discrete items, but rather as material streams as a result of shredding and separation or disassembly operations. This issue will need to be addressed when developing effective performance metrics for RSC, especially to calculate which products should be remanufactured, reused or recycled.

Porter and van der Linde (1995) acknowledge the need for regulation as a driver for improved environmental performance, whilst external pressures exerted by customers on suppliers and market competition drive innovation. This suggests that organisational economic objectives and environmental improvement need not be mutually exclusive. It is encouraging to note that the adoption of certain green practices in supply chain management can produce operational and economic benefits as well as improvements in environmental performance (Azevedo et al., 2011; Green et al., 2012; Rao and Holt, 2005).

According to Gunasekarana et al. (2004), the basic process steps behind embarking on performance measurement are identifying objectives, evaluating performance and subsequently decision making regarding future action. Hervani et al. (2005) argue that performance measurement is carried out for two broad reasons, namely external reporting and internal analysis/control. Internal audiences will include management and employees whilst external audiences will include regulators, pressure groups, customers, investors and so on. These audiences will change depending on the supply chain in question and the context it operates in. Similarly, their interests and goals may differ considerably, and hence also the metrics they would consider useful. Much of the supply chain literature examines more stable supply chains such as automobile or electronic goods. More complex and fluid supply networks involving textiles or food are by their nature, more difficult to control through performance measures (Jack, 2011) and thus present similar issues for RSC management. Ahi and Searcy (2015) developed a framework based on their literature review that attempts to direct performance measurement using a number of categories of metrics around a 'sustainability context', which is a high-level representation of the typical participants in a green supply chain.

In conclusion, there is currently no systematic approach for measuring the performance of a RSC, and further research into this complex issue is required.

\subsection{RSCs and EOL strategies}

The EOL strategy selected for a product will have an influence on performance measures and therefore the measurable effectiveness of the RSC. Rajagopalan and Yellepeddi (2007) illustrate an RSC network structure typical of a large original equipment manufacturer and offer methodologies for the measurement of the cycle time of value recovery and recommendations to reduce it. Rose and Stevels (2001) modelled the environmental performance of a number of consumer electronics products using data provided by Philips Consumer Electronics across their identified EOL strategies; reuse (second hand trading), service (life extension by repair or rebuild) remanufacture, recycling with disassembly, recycling without disassembly (using mechanical shredding and separation) and disposal (landfill or incineration, with or without energy recovery). 
Their findings indicate that for some products, EOL strategies commonly thought to be most beneficial in terms of environmental impact might offer little, if any, benefit in this respect.

In their comprehensive study concerning the eco-efficiency of consumer electronic products at the end of their lives, Huisman et al. (2004) applied a methodology to target minimal EOL treatment costs with maximum environmental recovery. They found the methodology to have capability in monitoring both the environmental and economic performance of individual materials, single products, and product groups in different EOL scenarios, thus assisting in EOL decision making for RSC operations. Srivastava and Srivastava (2006) suggested a conceptual model for RSC including the use of the environmental protection policy index and the green image and utility factor to optimise the reverse logistics network design. Organisations create unique supply chains and select different EOL solutions for their products. For that reason, the number of individual environmental performance metrics is large, even if many are quite similar in nature. Therefore, it is likely that each organisation will adopt a different process when considering what to measure and why. Indeed, Jasch (2000) argues that many organisations decide upon measures and then attempt to evaluate improvement rather than identifying targets using previous data to subsequently develop metrics for use in monitoring progress. In other words, the process of identifying metrics as part of a coherent and useful environmental performance management system is rather unreliable.

Kumar et al. (2016) point out that RSCs are increasingly recognised as essential, especially in a service context, where the physical flow of products may occur both in forward and reverse sense, including the delivery and returns of product returns from customers (Jack et al., 2010). In forward supply chains, inputs and outputs can be tangible or intangible (services, provision of information, customer-specific arrangements); typically, only tangible outputs can be returned (He et al., 2016). The focus of the research discussed in this article is mainly on cases where products are tangible and not in their original state any more when the RSC deals with them.

\section{The suggested framework}

A unifying framework could help companies understand and analyse their RSC. However, creating a generic model, applicable to any kind of RSC is very challenging due to the very diverse nature of the different scenarios across industries and countries. The suggested model aims to include all possible entities and processes. Some scenarios will encompass most of them, whereas others will only include a small selection. For instance, RSC for electronics typically include disassembly, remanufacturing, reengineering, reusing, recycling as well as disposal, whereas the RSC in the second markets in the food industry will be limited to charity, animal feeding and energy creation (anaerobic digestion or combustion).

\subsection{RSC operations}

The RSC deals with products returning to the manufacturer or third parties. Returns (or diversion to third parties) may be necessary because of a variety of reasons: 
1 products 'as new': too many items were ordered, or items being damaged, faulty, wrongly delivered or stock becoming obsolete

2 used products: damage and faults occurring during the product lifetime, requiring repair or overhaul

3 products at their EOL: no longer useful or wanted.

Fleischmann et al. (2001) suggested five classes of return flows:

1 EOL returns

2 commercial returns

3 warranty returns, i.e., failed products submitted for repair

4 production scrap and by-products

5 reusable packaging material.

Analysis shows that most of them will fall into the second and third cases above, with commercial returns referring to the first case.

The destination of a product in the RSC depends on several factors, including the remaining value (damage, size, material), the ease of disassembly or dismantling, the possibilities for reuse or recycling, the number of products at hand, and their nature. The case of products simply going to landfill is not typically considered an RSC scenario, although it is an EOL arrangement. RSC usually include elements of reuse, remanufacture/refurbishment, upgrading/upcycling or downcycling, recycling and energy production. Functional products often go on to a resale market, with or without warranty. In some cases, more than one iteration of an RSC process can take place, with products or materials going through several life cycles.

\subsection{Model}

Based on case studies taken from literature as well as direct interaction with industry, a generic model for RSC has been developed. Figure 1 show the typical processes involved in RSC, in accordance with Krumwiede and Sheu (2002). Examples are as follows, starting from the left:

Case 1 Electronic components taken from recovered computers may only need very slight cleaning or refurbishment before they are ready to be integrated into new products again, sold at full price and with full warranty.

Case 2 Returned vacuum cleaners may be remanufactured or repaired and then sold again at lower prices and typically with a reduced warranty.

Case 3 Cars are often resold without any processing and hence without warranty, at a lower price. The retained value is lower than in case 2 due to the lack of any actions to maintain or improve the state of the product.

Case 4 Metals are typically recycled and then sold again as primary materials. Recycled plastics often have degraded properties and hence will be sold at lower prices.

Case 5 Food waste can be digested anaerobically to produce methane that is then used to heat buildings. 
Some examples may not strictly follow the pattern shown in Figure 1, and combine characteristics from different cases. The processing by the original manufacturer, an independent company, or third party logistics partners may include the entire spectrum of inspection, testing, disassembly and sorting, or just some of the elements.

Figure 1 RSC types

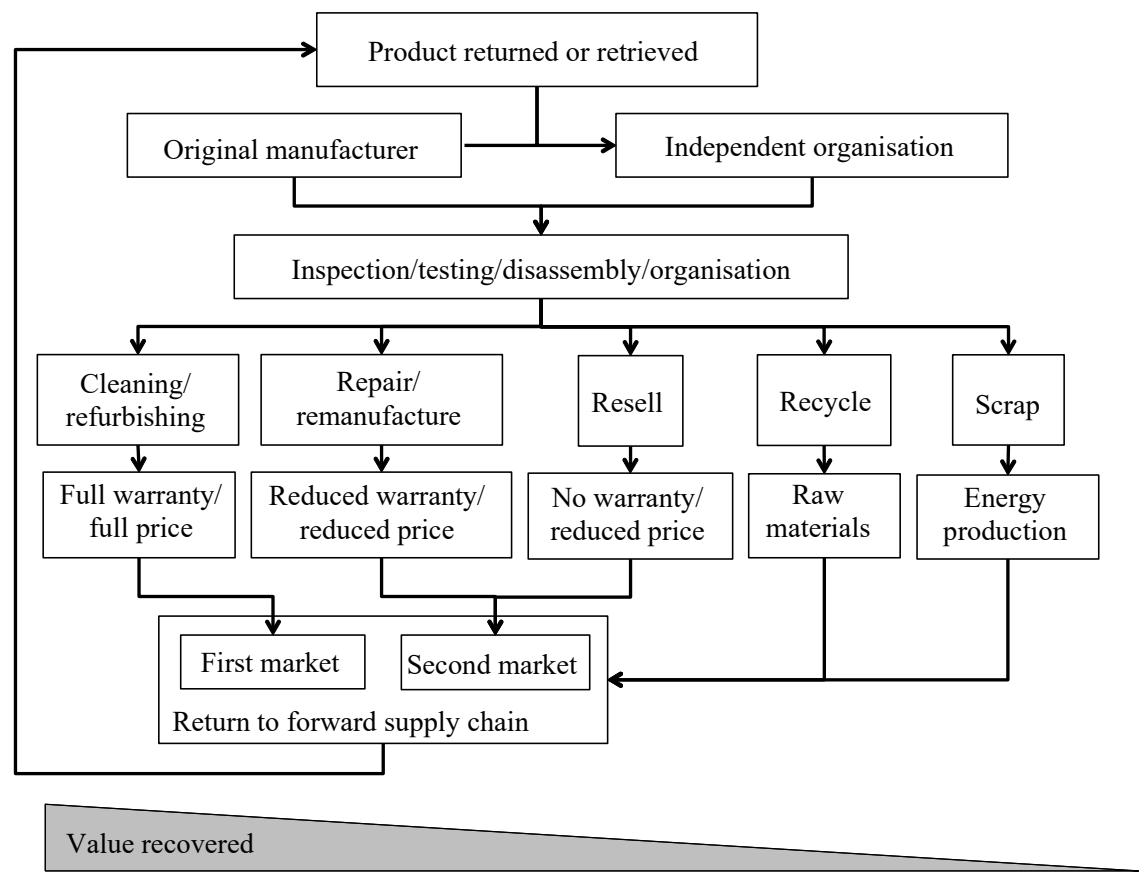

The processes to the left (remanufacturing, refurbishing) are generally thought to have the highest value retention rate and therefore may be the most desirable, whereas those to the right are considered to retain the least value and should be avoided if possible. These assumptions are subject to certain limitations and do not always hold true, particularly for energy consuming products, those with a short technology life cycle and those with a low purchase price. For example, the remanufacture of an inefficient energy-consuming product could be more detrimental to the environment than the recovery of its materials for use in a more efficient alternative. Similarly, accessing materials from the core of products may release considerable pollution, and the process may be hazardous for the workers. Nevertheless, over all, the extraction of these substances from waste may still be less harmful than the mining of virgin materials.

It may be worth noting that short technology life cycles can be extended with little or no refurbishment by targeting other markets for some products. For example, older cars exported to areas outside of Europe, North America and Japan are often used for many more years. Similarly, mobile phones that are obsolete in Europe are currently recovered from users by companies like Envirofone and then resold in Africa, Asia and South America where life cycles are much longer for the same product and a technology adoption lag exists. Interestingly, some of the refurbishment that does occur i.e., resetting back to factory setting is typically done by the person owning the item before sending to 
Envirofone. In this sense, personal privacy protection saves some refurbishment costs for the reseller.

In developed countries, the resale market for remanufactured or repaired technology is likely to diminish as that technology ages - it may be viable to refurbish a mobile phone that is relatively 'current', but this is unlikely to be the case for an older model. However, resale markets in developing countries will often absorb products that are no longer desired or acceptable elsewhere. Factors including lower quality standards, a weak forward supply chain, poor communication technology infrastructure, under-developed regulation and corruption in developing countries contribute to this (Brooks, 2012). Therefore, the EOL strategy may require a reappraisal of how product life cycles differ in different markets for recovered products. To that end, as resource recovery is a global issue, it may be wise to not be too parochial with regard to product life cycle observations as they can be different across the world even for the same product.

Products going to landfill should be the very last resort, as nothing can be gained from the process. Depending on what kinds of materials are being scrapped, there may be two better alternatives: incineration or anaerobic digestion (Gorgec et al., 2016). In the case of incineration, the generated energy can be used directly to heat buildings. Similarly, the methane gained from anaerobic digestion can be used as fuel for a variety of operations. Both scenarios require investments into infrastructure as well as running and maintaining the facilities. It has, however, been shown with the Kalundborg town (Valentine, 2016) that this can be done at an economic benefit.

\section{Analysis of shared characteristics}

Engaging in RSC activities is most interesting for companies when the products, parts or materials to be retrieved are of high value, scarce or need to be protected from third parties. Besides financial benefit, reasons to engage include improving corporate image in terms of ethical or moral responsibility, or the market requesting recycled, eco-friendly and socially sourced products, as well as the need to comply with environmental regulations. Although environmental quality standards (ISO 14001) are currently voluntary, they are increasingly adopted. The motivations for adoption are numerous such as a requirement to remain on a procurement list, the awareness that a competitor has it, or simply to improve business processes. Part of the standard is product life cycle analysis (ISO 14040). This provides a framework for an ongoing process of iterative design improvement for reducing environmental impact through better choice of materials, design for recovery and so on. Therefore, adoption of quality standards is for many companies the manifestation of RSC and can/should cut across the entire organisation.

Seitz (2007) furthermore identified warranty aspects, securing a spare parts supply, gaining market share and assuring brand protection, as well as customer orientation as factors why automotive companies will conduct remanufacturing. In the EU, legal requirements also play an important role, obliging manufacturers to recycle materials. For instance, $85-95 \%$ of a Volvo truck is recyclable and about a third by weight of the materials used in a new truck is from recycled materials. Furthermore, disassembly instructions are available (Volvo, 2016).

When retrieving products or components for reuse or remanufacturing, it is essential that they incur as little damage, wear and tear over time. Steinhilper (2001) identified 
eight types of criteria for evaluating the suitability of a product for remanufacturing, including technical criteria, the number of available products, their value, life cycle duration, technological innovation, market characteristics and others.

In cases like a car manufacturer refurbishing used engines, it is the original manufacturer organising the RSC (possibly outsourcing the logistics of it) and taking care of the product in-house. However, this is not always the case. Especially when the focus is on retrieving materials for recycling, third party companies are often taking over. For them, it is almost like running a forward supply chain, except that the materials are being sourced from more diverse locations. For the sake of a circular economy (Weetman, 2016), it is secondary who organises and executes the RSC, as long as the parts or materials are being fed back into the circle of usefulness. However, the retained value and the energy invested in the reverse process does matter. Options that retain more value and involve less transformative processes usually require less energy, happen in a shorter time frame from the original product sale and have a higher probability of OEM involvement, as illustrated in Figure 2.

Figure 2 Often, OEMs are less involved in RSC cases that retain little value, undergo significant transformations of the products and require a lot of energy and take a long time

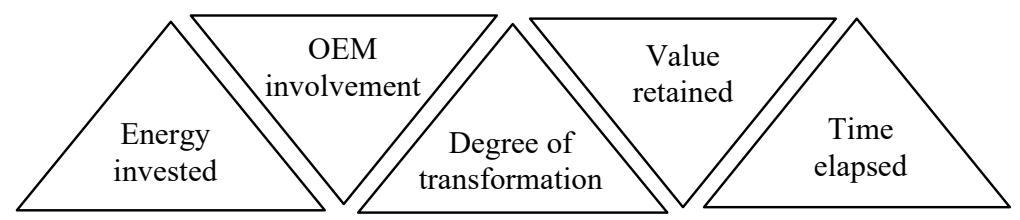

In terms of energy and effort to be invested in the process, reuse 'as is' would be the most convenient option. Examples for this case include second hand cars that may need no more than inspection. Products that can be repaired or refurbished would follow, and at first sight, it may seem better to repair and reuse existing products if possible, avoiding their disposal as well as the manufacture of new ones. However, with the progress in technology, many updated products (e.g., car engines) become much more efficient. Hence it may be ecologically and economically more sensible to replace an old product by a new one. This is the case if the running cost and environmental effects of the old product over a certain period of time are greater than the purchase cost, running cost and environmental effects of new product over the same period of time.

Products that need to be disassembled for the retrieval of reusable components or to gain access to certain materials used in their core (e.g., precious metals in electronic products) pose an additional challenge. As mentioned previously, the disassembly is usually done manually and with considerable effort. This means that most of these products get shipped to lower wage countries for economical reasons, increasing their environmental impact with transportation and possibly less socially and environmentally favourable conditions than in the country of use.

Disassembly can be challenging. It usually has to be done manually and in an ad hoc manner due to variations between different brands of products, generations of products, modifications and damage. It becomes easier if the original manufacturer is involved and still has access to the construction plans, as well as when the lifetime of the product was shorter. This is an argument - broadly in line with the 'polluter pays' principle that guides much of the law in the UK and Europe - for increasingly shifting the ownership of products towards the manufacturer, using a product service system (PSS), further 
discussed subsequently. In such a scenario, the manufacturer has a major interest in designing the product for frequent upgrade, easy repairs, simple disassembly, as well as reuse of components or recycling of materials. Modular designs will be favoured. The major challenge, which most likely requires a suitable legal framework and corresponding policies, is getting manufacturers to take life-long responsibility for their products (as promoted by product life cycle analysis, ISO 14040), and for customers to fully accept the PSS business model (Baines et al., 2007).

\subsection{Identification of critical factors}

The conservation of value is essential across the entire RSC (Weetman, 2016). It starts when the product is retrieved - the earlier in its life cycle the better - and continues through logistics to treatment and possible resale. Many products will lose value over time, even if their physical state does not otherwise change, as products on the market are replaced by newer models. Additionally, some materials will suffer from exposure to radiation, humidity or dust. The handling and processing of the products will also play a major role in terms of value conservation, as it may lead to damage and hence limit the possibilities for reuse or remanufacturing.

The cost of processing will contribute to determining how much profit may result from the RSC. Processing includes collection, transportation, sorting, inspection, testing as well as disassembly, repair, remanufacturing, etc.

Moreover, looking at the bigger picture, the cost should also include the effects of the RSC on the environment and society as a whole. On the negative side, further pollution may be caused and the local population's health may be harmed. On the positive side, jobs may be created and the need for exploiting further natural resources be reduced.

The consequences of not engaging in the RSC for companies and generally the economy, society and environment also need to be considered. This includes the effects of sourcing new materials rather than using existing ones and manufacturing new products as well as the need to deal with the waste from discarded ones. OEMs may miss opportunities to recover value and lose market shares to independent companies who are willing to engage in the RSC. Controlling the returns will also allow companies to ensure that spare parts do not end up being sold into a 'grey market' that may have additional detrimental effects on the business, such as counterfeiting. The protection of Intellectual Property is a reason for companies to engage in RSC (Martin et al., 2010).

The lack of engagement in terms of sustainability may negatively affect the OEM's corporate image and lead to customers favouring more responsible brands. This requires a more flexible, pragmatic or even enlightened approach to brand positioning, as Patagonia Clothing demonstrate, encouraging a market of used garments being resold. Furthermore, original manufacturers may miss the opportunity to get feedback on product reliability and durability, to access lower-priced markets, and fail to establish or maintain a reputation for quality (Matsumoto and Umeda, 2011).

The acceptance of refurbished products by the customer (Abbey et al., 2015) will, among other factors, depend on how the products are brought to the market: with or without warranty; at a reduced, full or increased price; through which sales channels; with or without an eco label or 'feel good factor'. In many cases, the demand for remanufactured products will also depend on the awareness of the customers that these products are actually available, and the ease for the customer to access them. 
The quality of recycled materials or product components in comparison to new materials is an important factor as well (Ravi, 2012). In some cases, recycled components or materials show lower levels or performance than new ones, and manufacturers may need to adapt their product designs to deal with this. In other cases, the quality is not affected, or even improved (e.g., no wear-in phase for remanufactured engines). The issue with the quality loss the materials may suffer during reprocessing is sidestepped when repurposing old products, e.g., old car tyres becoming safe children's playground surfaces or even old plastic bottles being reprocessed into garments.

The varying interests of stakeholders and their respective degree of influence play a defining role in how an RSC is organised. For instance, a system that is created for keeping spare parts off the black market will operate in a very different way than a network of community-organised recycling points, or the returns system of a major retailer. As a consequence, when analysing RSC, it is essential to be aware of the major stakeholders and their goals. The current rules and regulations for dealing with waste provide a framework in which organisations operate, and in many cases is still the only reason companies engage in any kind of RSC - at least in the beginning. Numerous studies have found that in most countries, the legal framework is still not stringent enough (or not sufficiently enforced) to push companies to engage in effective $\mathrm{CE}$ activities. As an example, cross-border transport of e-waste is forbidden in many countries, yet it still happens at a large scale (Bisschop, 2012). It remains an open question if instead of forbidding its transport, it would not be preferable to create and enforce rules for dealing with e-waste in more responsible ways. The difficulty is then the lack of jurisdiction of the sending country in the receiving one. The key might be for all parties to understand that there is only one Earth, and pollution does not stay within political borders.

Ethical issues of many kinds will have to be dealt with when organising RSC. This is also true for forward supply chains, but they may be easier to ignore due to the nature of the product flows - until the media sporadically reveal them, such as when major corporations use suppliers and subcontractors that treat their workers in slave-like ways (SACOM, 2016). Whilst many RSC are run for financial benefit primarily, others are created due to environmental and social reasons, and hence there is more sensitivity for ethical aspects.

Last but not least, fraud in the RSC can seriously affect companies. For instance, many online retailers face return rates of 20 to $40 \%$ and in certain cases even more (Weverbergh, 2016). This is a considerable quantity, and provides multiple opportunities for malicious fraud (or unintentional mistakes) of various sources: customers, third party logistics handlers, and company employees of various functions. This is a risk that applies to most cases of RSC, and companies will need to take preventative measures to avoid losing money, quality and credibility (Jack, 2015).

\section{Analysis and discussion}

Companies looking to evaluate the environmental performance of their RSC operations should consider the total environmental impact of the EOL strategies selected for their products. This means looking outside of the supply chain effects and taking a holistic view. 
Rose and Stevels (2001) argue that that the popular belief that reuse is the best EOL strategy to reduce environmental impact is only partly true. Reuse (including remanufacture or refurbishment to reuse) of an inefficient energy-consuming product or appliance and extension of its working life may have a greater environmental impact than recovery or recycling of its components and materials. Old cars and building heating/cooling systems illustrate this problem. In the future, the reuse of such products and appliances may become difficult as a result of consumers opting to purchase more efficient and therefore cheaper to operate alternatives or even impossible due to legislation forcing the removal of such products from the market. The phasing out of incandescent light bulbs and the recent prohibition on vacuum cleaners with motors exceeding 1,600 W in Europe demonstrates the EU's commitment to energy saving. It is possible that measures such as these could be taken to address other energy-consuming products in the future.

Most companies will seek to maximise value recovery in the selection of the EOL strategies for their products. The potential value that can be recovered from a product often diminishes over time. For example, electrical products that are quickly superseded such as mobile phones and computers, seasonal goods from the fashion and events industries and perishable goods, such as food, medicines, flowers and cosmetics. This has implications on EOL strategy and the design and operation of the RSC itself. This applies both to the economic and environmental aspects of an RSC operation.

It may be the case for some products that certain strategies offer a better financial return than others. For example, a refurbished laptop may offer less in terms of economic value recovery than could be realised by dismantling and reusing its materials, which may hold or in some cases even increase its value over time. Of particular significance for those products that more readily decline in value is the 'cycle time of value recovery' of the product. In their study of the development of methodology for measuring value recovery time of returns, Rajagopalan and Yellepeddi (2007) define this as "the time taken by the returned product to traverse from the first operation in the RSC to the last one". Clearly the more complex the operation to recovery value, the greater the cycle time of value recovery and the bigger the cost, hence the smaller the recovered value. Furthermore, there is usually considerable uncertainty surrounding the quality and quantity of returned goods.

\subsection{Business models supporting prolonged and repeated product life cycles}

The PSS business model, also known as servitisation (Dachs et al., 2014), where companies provide a service based on their product, rather than just a product to be purchased, solves the issue of manufacturers not giving much importance to the EOL solutions of the products they make. Rather than selling a product and no longer being responsible for it, companies that sell a service typically provide equipment to their customers on loan and deliver maintenance, repair and periodic replacement. This means that companies keep the responsibility for the equipment and are therefore interested in options for disassembly and refurbishment or whichever EOL solution is selected for the product. The service business model hence facilitates the engagement in RSC and contributes to reducing waste.

Another solution to this problem is for companies to actively seek to retrieve used products from the end user whilst the product is in a known condition. This strategy is likely to be most successful when the user is required or compelled to return a product to 
an established collection point for their own benefit. This principle is illustrated by domestic gas canisters or disposable cameras, for example, which the customer needs to take to a collection point for it to be processed, replenished or replaced. In these cases, the quantity and quality of returned products would be more predictable. Financial incentives, such as discounts on new products when returning used ones may also help to improve return rates. For items that cannot be disposed of with general household waste the benefit to the consumer in this case is twofold, as they need not make a separate visit to a product disposal facility or pay for it to be collected.

Similarly, many companies selling larger home appliances (which are typically delivered rather than collected by the consumer) offer to remove and dispose of the used product at no cost the customer. The advantages of this strategy include that the company can predict approximately how many appliances will be returned and the capacity of the delivery lorries can be used in both directions. Companies could even request advance information from the customers regarding the types, brands and states of the returned appliances.

\subsection{Reasons for companies to engage in RSCs}

It is a common belief that running an RSC is beneficial for the environment but financially disadvantageous. This is especially the case with products that have not been designed with disassembly and reuse in mind, and when products retain little value. In these cases, companies may operate an RSC because legislation demands it, or because it is favourable for the corporate image. Successful examples of RSCs often retrieve valuable, scarce or high-energy materials. Some companies use remanufactured components or recycled materials to lower manufacturing costs. Steel is very prominent example of this principle: the UK are large exporters of scrap steel to China and India where steel is recycled and then sold back to the UK, at prices that are lower than those paid for newly gained steel from the UK. However, Arc furnaces in the UK now produce recycled steel that is also significantly cheaper than newly gained UK produced steel.

Hence, whilst Chinese recycled steel may still be cheaper on the face of it, it is necessary to also consider the bigger picture: the effects of global transport, the lower regulation of industrial pollution caused by coal-fuelled Chinese power stations, water contamination and poor waste disposal in China and less stringent health and safety regulations. Taking all this into account, any cost differential becomes far less clear-cut: exporting our pollution may give the false appearance of 'greening' our supply chains when production in China or India is not clean even if the product is recycled steel. As stated before, companies need a more rounded view of their supply chains because cheapness is more than sales prices or financial metrics in general. If finance is the main metric, it becomes a lagging index of a performance measurement system that is internally focused and not adequate for RSC (Caplice and Sheffi, 1995).

Certain electronics manufacturers are known to use refurbished components in new devices, as they are cheaper to source. In other cases, car manufacturers remanufacture used engines and even sell them at higher prices due to the engines not needing any wear-in period the second time. BMW actively promote the fact that they use recycled materials in their new cars on their websites. For Volvo and BMW, this is in no small part due to EOL vehicles (producer responsibility) regulations 2005, no.263 derived from EU directive 2000/53/EC that requires manufacturers to provide a convenient network of facilities to receive EOL vehicles. 
For more companies to engage in RSC activities, the EOL strategy selected for a product is key. This can be most successfully addressed at the design stage. A difficulty lies in the fact that the stakeholders are often not the same; product designers are rarely aware of the requirements for dismantling and reuse, and those dealing with RSC rarely have any say in product design - a few examples of exceptions are given below. In addition to that, too often procurement and supply chain managers are excluded from the early stages of new product development, which has the effect of new materials being specified rather than recovered materials/components, unless regulation requires it. In the automotive sector, for example, once materials are specified at detailed component level and the design phase ends, it may prove highly expensive and very slow to change specification (or even supplier). As a consequence, materials are not easily changed once they form parts of drawings and specifications. This is in part the effect of TS 16949 Quality standard for automotive manufacturers and suppliers, derived from ISO 9001. The EU Restriction of Hazardous Substances, RoHS - Directive 2002/95/EC (now replaced by RoHS 2 - Directive 2011/65/EU), had serious effects on this across all sectors of European manufacturing as it forced manufacturers and suppliers to consider recycling and disposal as part of their design processes.

Finally, many products are designed for shorter life cycles than was the case in the past e.g., TVs and washing machines. This suggests corporations favour regular repeat sales over servicing and repair, meaning that they prioritise their forward supply chain over the RSC, and their shareholding stakeholders to the detriment of environmental stakeholders.

Further challenges are identified by Rose et al. (1998), such as advancements in recycling and value recovery technology and material commodity market fluctuations. They argue that "only by accurately predicting the end-of-life strategy of products can designers and recycling technology developers actually incorporate design for environment". They also identify a range of factors and characteristics that affect the recyclability and therefore the optimum EOL solution for a given product. From their case studies they observed that a relationship exists between the wear-out life, technology cycle and EOL path for certain products.

\subsection{Examples of RSC}

Whilst the majority of businesses still mostly ignore their RSC, there are many examples where the RSC is fully functional and benefits the companies as well as society and the environment. The following list describes a few cases; further and more detailed case studies are described in Frei (2016).

1 Dismantling of ships (Iliopoulos, 2015), cars and aircraft: specialised dismantling plants deal with ships and aircraft once they have reached the end of their useful life. Most ships will be taken apart in India and Bangladesh, but also in China, Turkey and the Netherlands. Aircraft disassembly is done along the border between France and Spain as well as in Arizona, USA. Cars are being demolished in many local plants all around the world, whilst some of them go to second markets in developing countries.

2 Combustion gas bottles: used for camping, mobile business applications and households without central gas supply, gas bottles are refilled by local retailers. 
3 Remanufactured electronics: some devices are openly declared as refurbished by the manufacturer and sold at $75 \%$ of original price, with a full product warranty.

4 Remanufactured electronic components: for instance, hard drives are often refurbished by manufacturers and then placed in new computers, sold at full price. In this case, the customer is not aware that some components have been used previously.

5 Refurbished photocopiers and printers: some devices have an average of seven life cycles (Chiodo and Ijomah, 2014), with many components being reused whilst others are being exchanged.

6 Whilst efforts are being made to recycle unused or regained materials in construction industry, with collection containers being placed at major construction sites, the reuse of materials is still facing many barriers (Chileshe et al., 2015).

7 In fashion retail, second markets are particularly interesting for high-priced brands sold at reduced prices in outlets and off-price stores (Beh et al., 2016). Customers buy a high-quality product from overstock or returns at a lower price.

8 A pilot project returning spare parts for medical equipment back to the manufacturer (Pham, 2015) is motivated by keeping the parts off the black market firstly and secondly by possible financial benefits.

Table 1 Example of RSC cases

\begin{tabular}{|c|c|c|}
\hline Type of RSC & Example & Engaged parties \\
\hline \multirow{4}{*}{$\begin{array}{l}\text { Inspect/repair } \\
\text { and onto first } \\
\text { market }\end{array}$} & Combustion gas bottles & Consumer, retailer, manufacturer \\
\hline & Electronics sold at full price & Consumer, retailer, manufacturer \\
\hline & Photocopiers & Consumer, retailer, manufacturer \\
\hline & Spare parts returned & Manufacturer, suppliers \\
\hline \multirow{2}{*}{$\begin{array}{l}\text { Repair/refurbish } \\
\text { and onto resale } \\
\text { market }\end{array}$} & Electronics sold at lower price & (Consumer, retailer), manufacturer \\
\hline & Off-price fashion & Retailer, off-price trader \\
\hline \multirow[t]{2}{*}{$\begin{array}{l}\text { Recycle and } \\
\text { resell materials }\end{array}$} & Dismantling of ships & $\begin{array}{l}\text { Ship owner, EOL ship trader, ship } \\
\text { dismantling company }\end{array}$ \\
\hline & Recycling of construction materials & $\begin{array}{l}\text { Builders, recycling companies, } \\
\text { manufacturers }\end{array}$ \\
\hline $\begin{array}{l}\text { Scrap and } \\
\text { capture energy }\end{array}$ & $\begin{array}{c}\text { Burning or organic digestion of } \\
\text { materials }\end{array}$ & Waste management companies \\
\hline
\end{tabular}

Table 1 categorises the RSC examples according to the model illustrated in Figure 1 and lists the typically involved parties. It is interesting to observe that with products being inspected or repaired and going back onto the first market, the original manufacturer is most often involved and in charge of running the RSC. In this case, the most value is recovered. The less value is recovered (and the further to the right in Figure 1), the less likely it is that the original manufacturer is involved, and third parties are running the RSC instead. In these situations, the RSC deals with a wider variety of products and materials, and has less control of their origin and condition, and generally less is know about them. An interesting development to mend this situation is happening in the ship industry, where Maersk are developing a 'cradle-to-cradle passport' for the new 
generation of major vessels, containing information about the materials used in the ship and any changes made during its lifetime (Maersk, 2014; Sterling, 2011).

Figure 3 shows an RSC run by the original manufacturer with the essential possibility of providing feedback from process involving disassembly/inspection/remanufacturing to the design and manufacturing stage. Whilst this would theoretically also be possible when third parties are involved in the RSC, it is more difficult to get the original manufacturer to pay attention to the feedback, and even more challenging to get them to implement any changes that are unlikely to directly affect them.

Figure 3 Feedback from recovered products for the benefit of new or improved designs

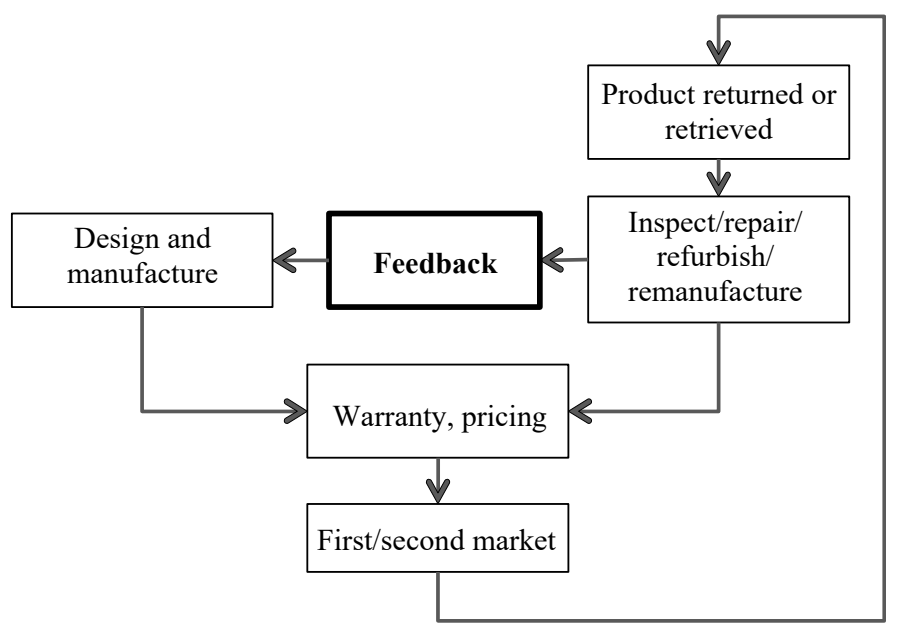

\section{Conclusions and recommendations}

This article addressed the following research questions:

Q1 What is the current state of the art in understanding different types of RSC and assessing their performance?

A1 The literature review refers to relevant existing work, concluding that a research gap exists regarding both the modelling of RSC and the assessment of their performance.

Q2 What different types of RSC exist and how do they relate to each other?

A2 To this purpose, numerous examples of RSC were presented and a unifying framework was introduced, together with an assessment of the stakeholders and their interests.

Q3 What factors influence companies' decisions to engage in RSC and what factors decide whether or not an RSC will be successful?

A3 This article has highlighted some of the challenges associated with establishing, operating and monitoring RSC operations and some potential solutions to these problems. Shared characteristics and critical factors have been identified. 
To assess the performance of RSC as well as to advise policy makers and company directors on how to best shape a framework for guiding RSC and how to best organise RSC operations, an even deeper understanding is necessary. Further research should be conducted to create a comprehensive RSC decision making tool, which includes EOL solution optimisation for maximising the environmental and economic performance of the RSC. This should include a mechanism for comparing the effects of continued use of inefficient products, including possibly necessary refurbishments and repairs, versus the production of new efficient products, their use, and the proper disposal/recycling of the discarded products.

\section{Acknowledgements}

This work was supported by the EPSRC Digital Economy Sustainable Society Network + .

\section{References}

Abbey, J.D., Meloy, M.G., Blackburn, J. and Guide, V.D.R. (2015) 'Consumer markets for remanufactured and refurbished products', California Management Review, Vol. 57, No. 4, pp.26-42.

Ahi, P. and Searcy, C. (2015) 'An analysis of metrics used to measure performance in green and sustainable supply chains', Journal of Cleaner Production, Vol. 86, pp.360-377.

Azevedo, S.G., Cercalho, H. and Machado, V.C. (2011) 'The influence of green practices on supply chain performance: a case study approach', Transportation Research Part E, Vol. 47, pp.850-871.

Bai, C.S., Wei, X. and Koh, L. (2012) 'Evaluating ecological sustainable performance measures for supply chain management', Supply Chain Management: An International Journal, Vol. 17, No. 1, pp.78-92.

Baines, T.S., Lightfoot, H.W., Evans, S., Neely, A., Greenough, R., Peppard, J. and Alcock, J.R. (2007) 'State-of-the-art in product-service systems', Proceedings of the Institution of Mechanical Engineers, Part B: Journal of Engineering Manufacture, Vol. 221, No. 10, pp.1543-1552.

Beh, L.S., Ghobadian, A., He, Q., Gallear, D. and O'Regan, N. (2016) 'Second-life retailing: a reverse supply chain perspective', Supply Chain Management: An International Journal, Vol. 21, No. 2, pp.259-272, Pre-Print.

Bisschop, L. (2012) 'Is it all going to waste? Illegal transports of e-waste in a European trade hub', Crime, Law and Social Change, Vol. 58, No. 3, pp.221-249.

Bjorklund, M., Martinsen, U. and Abrahamsson, M. (2012) 'Performance measurements in the greening of supply chains', Supply Chain Management: An International Journal, Vol. 17, No. 1, pp.29-39.

Brooks, A. (2012) 'Networks of power and corruption: the trade of Japanese used cars to Mozambique', The Geographical Journal, Vol. 178, No. 1, pp.80-92.

Callado, A.A.C. and Jack, L. (2015) 'Balanced scorecard metrics and specific supply chain roles', International Journal of Productivity and Performance Management, Vol. 64, No. 2, pp.288-300.

Caplice, C. and Sheffi, Y. (1995) 'A review and evaluation of logistics performance measurement systems', International Journal of Logistics Management, Vol. 6, No. 1, pp.61-74.

Chileshe, N., Rameezdeen, R., Hosseini, M.R. and Lehmann, S. (2015) 'Barriers to implementing reverse logistics in South Australian construction organisations', Supply Chain Management: An International Journal, Vol. 20, No. 2, pp.179-204. 
Chiodo, J.D. and Ijomah, W.L. (2014) 'Use of active disassembly technology to improve remanufacturing productivity: automotive application', International Journal of Computer Integrated Manufacturing, Vol. 27, No. 4, pp.361-371.

Dachs, B., Biege, S., Borowiecki, M., Lay, G., Jäger, A. and Schartinger, D. (2014) 'Servitisation of European manufacturing: evidence from a large scale database', The Service Industries Journal, Vol. 34, No. 1, pp.5-23.

El Barky, S.S. (2016) 'Impact of reverse logistics application in terms of return policy and remanufactured product quality on customer satisfaction', Int. J. of Supply Chain and Operations Resilience, Vol. 2, No. 2, pp.95-113.

El Baz, J., Frei, R. and Laguir, I. (2016) 'Exploring reverse supply chain practices in Morocco', International Conference Project and Logistic (PROLOG), Agadir, Morocco.

Fleischmann, M., Beullens, P., Bloemhof-Ruwaard, J.M. and Wassenhove, L.N. (2001) 'The impact of product recovery on logistics network design', Production and Operations Management, Vol. 10, No. 2, pp.156-173.

Frei, R. (2016) 'Reverse supply chains', in Weetman, C. (Ed.): A Circular Economy Handbook for Business and Supply Chains, Kogan Page, London, UK.

Frei, R., Lothian, I., Bines, A., Butar Butar, M. and Da Gama, L. (2015) 'Performance in reverse supply chains', Paper presented at Logistics Research Network Annual Conference (LRN), Derby, UK [online] http://reginafrei.ch/publications_year.html (accessed 12 March 2016).

Gorgec, A.G., Insel, G, Yağci, N., Doğru, M., Erdincler, A., Sanin, D., Filibeli, A. and Keskinler, B. (2016) 'Comparison of energy efficiencies for advanced anaerobic digestion, incineration, and gasification processes in municipal sludge management', Journal of Residuals Science and Technology, Vol. 13, No. 1, pp.57-64.

Green, K.W.J., Zelbst, P.J., Vikram, J.M. and Bhadauria, S. (2012) 'Green supply chain management practices: impact on performance', Supply Chain Management: An International Journal, Vol. 17, No. 3, pp.290-305.

Guide, V.D. and van Wassenhove, L. (2002) 'The reverse supply chain', Harvard Business Review, Vol. 80, No. 2, pp.25-26.

Gunasekarana, A., Patel, C. and McGaughey, R. (2004) 'A framework for supply chain performance measurement', International Journal of Production Economics, Vol. 87, pp.333-347.

He, Q., Ghobadian, A., Gallear, D., Beh, L.S. and O'Regan, N. (2016) 'Towards conceptualizing reverse service supply chains', Supply Chain Management: An International Journal, Vol. 21, No. 2, pp.166-179, Pre-Print.

Hervani, A., Helms, M. and Sarkis, J. (2005) 'Performance measurement for green supply chain management', Benchmarking: An International Journal, Vol. 12, No. 4, pp.330-353.

Huisman, J., Stevels, A.L.N. and Stobbe, I. (2004) 'Eco-efficiency considerations on the end-of-life of consumer electronic products', IEEE Transactions on Electronics Packaging Manufacturing, Vol. 27, No. 1, pp.9-25.

Iliopoulos, C. (2015) Reverse Supply Chain of Ships, MSc thesis, School of Engineering, Faculty of Technology, University of Portsmouth, UK [online] http://reginafrei.ch/projects.html (accessed 12 March 2016).

Jack, E.P., Powers, T.L. and Skinner, L. (2010) 'Reverse logistics capabilities: antecedents and cost savings', International Journal of Physical Distribution and Logistics Management, Vol. 40, No. 3, pp.228-246.

Jack, L. (2011) 'Inter-organisational performance measurement practices between supply chain partners: issues for the agri-food industry', in Abdel-Kader, M. (Ed.): Review of Management Accounting Research, pp.479-496, Palgrave Macmillan, Basingstoke [online] https://researchportal.port.ac.uk/portal/en/persons/lisa-jack(18f87e2e-295b-4e22-ac5bb0a6740f769f).html (accessed 9 October 2016). 
Jack, L. (2015) Risk Modelling of Food Fraud Motivation: 'NSF Fraud Protection Model' Intelligent Risk Model Scoping Project FS 246004: Final Report [online] http://eprints.port.ac.uk/16980/1/JACK_2015_pub_NSF_report_Risk_Modelling_Of_Food_Fr aud_Motivation.pdf (accessed 9 October 2016).

Jasch, C. (2000) 'Environmental performance evaluation and indicators', Journal of Cleaner Production, Vol. 8, pp.79-88.

Krumwiede, D.W. and Sheu, C. (2002) 'A model for reverse logistics entry by third-party providers', Omega, Vol. 30, No. 4, pp.322-333.

Kumar, V., Amorim, M., Bhattacharya, A. and Garza-Reyes, J.A. (2016) 'Managing reverse exchanges in service supply chains', Supply Chain Management: An International Journal, Vol. 21, No. 2, pp.157-165, Pre-Print.

Lee, S. (2008) 'Drivers for the participation of small and medium-sized suppliers in green supply chain initiatives', Supply Chain Management: An International Journal, Vol. 13, No. 3, pp.185-198.

Lee, S. and Rhee, S. (2007) 'The change in corporate environmental strategies: a longitudinal empirical study', Management Decision, Vol. 45, No. 2, pp.196-216.

Maersk (2014) Cradle to Cradle [online] http://www.maersk.com/en/hardware/triple-e/the-hardfacts/cradle-to-cradle (accessed 12 March 2016).

Martin, P., Guide, V.D. and Craighead, C.W. (2010) 'Supply chain sourcing in remanufacturing operations: an empirical investigation of remake versus buy', Decision Sciences, Vol. 41, No. 2, pp.301-324.

Matsumoto, M. and Umeda, Y. (2011) 'Analysis of remanufacturing practices in Japan', Journal of Remanufacturing, Vol. 1, No. 2, pp.1-11.

McElroy, M. and Engelen, J. (2012) Corporate Sustainability Management: The Art And Science of Managing Non-Financial Performance, Earthscan, London and New York.

Morana, J. (2013) FOCUS Series: Sustainable Supply Chain Management, Wiley, Somerset, NJ, USA.

Pham, L. (2015) 'Reverse Supply Chain of Medical Equipment, MSc thesis, School of Engineering, Faculty of Technology, University of Portsmouth, UK [online] $\mathrm{http}: / /$ reginafrei.ch/projects.html (accessed 12 March 2016).

Porter, M.E. and van der Linde, C. (1995) 'Green and competitive: ending the stalemate', Harvard Business Review, Vol. 73, No. 5, pp.120-134.

Prahinski, C. and Kocabasoglu, C. (2006) 'Empirical research opportunities in reverse supply chains', The International Journal of Management Science, Vol. 34, pp.519-532.

Rajagopalan, S. and Yellepeddi, S. (2007) 'Development of methodology for measuring and reducing value recovery time of returns', Proceedings of Management of Engineering and Technology, Portland, USA, pp.2336-2344.

Rao, P. and Holt, D. (2005) 'Do green supply chains lead to competitiveness and economic performance?', International Journal of Operations and Production Management, Vol. 25, No. 9, pp.898-916.

Ravi, V. (2012) 'Evaluating overall quality of recycling of e-waste from end-of-life computers', Journal of Cleaner Production, Vol. 20, No. 1, pp.145-151.

Rose, C.M. and Stevels, A. (2001) 'Metrics for end-of-life strategies (ELSEIM)', Proceedings of the IEEE International Symposium on Electronics and the Environment, pp.100-105.

Rose, C.M., Ishii, K. and Masui, K. (1998) 'How product characteristics determine end-of-life strategies', Proceedings of the IEEE International Symposium on Electronics and the Environment, Oak Brook, IL, USA, pp.322-327.

SACOM (2016) Students and Scholars Against Corporate Misbehaviour [online] http://sacom.hk/media-type/investigative-reports/ (accessed 9 October 2016).

Seitz, M.A. (2007) 'A critical assessment of motives for product recovery: the case of engine remanufacturing', Journal of Cleaner Production, Vol. 15, pp.1147-1157. 
Srivastava, S. and Srivastava, R. (2006) 'Managing product returns for reverse logistics', International Journal of Physical Distribution and Logistics Management, Vol. 36, No. 7, pp.524-546.

Steinhilper, R. (2001) 'Recent trends and benefits of remanufacturing: from closed loop businesses to synergetic networks', International Symposium on Environmentally Conscious Design and Inverse Manufacturing (EcoDesign), Tokyo, Japan.

Sterling, J. (2011) 'Cradle to cradle passport - towards a new industry standard in ship building', OECD Workshop on Green Growth in Ship Building.

Svensson, G. (2007) 'Aspects of sustainable supply chain management (SSCM): conceptual framework and empirical example', Supply Chain Management: An International Journal, Vol. 12, No. 4, pp.262-266.

Valentine, S.V. (2016) 'Kalundborg symbiosis: fostering progressive innovation in environmental networks', Journal of Cleaner Production, Vol. 118, pp.65-77.

Volvo (2016) Using the Good Materials All Over Again [online] $\mathrm{http}$ //www.volvotrucks.com/trucks/uk-market/en-gb/aboutus/environmentnew/recycling/Pages/recycling.aspx (accessed 26 April 2016).

Weetman, C. (2016) A Circular Economy Handbook for Business and Supply Chains, Kogan Page, London, UK.

Weverbergh, R. (2016) E-Commerce: Why and How Often Customers Send Stuff Back [Survey] [online] http://www.whiteboardmag.com/e-commerce-why-and-how-often-customers-sentstuff-back-survey/ (accessed 9 October 2016). 